\title{
Diseminasi Hukum Humaniter Internasional Dalam Upaya Menyebarkan Semangat Perdamaian
}

\author{
Yordan Gunawan $^{\mathrm{a}, 1^{*}, \text { Naufal Bagus Pratama }}{ }^{\mathrm{b}, 2}$ \\ ${ }^{\mathrm{a}, \mathrm{b}}$ Fakultas Hukum, Universitas Muhammadiyah Yogyakarta, Bantul \\ Iyordangunawan@umy.ac.id; ${ }^{2}$ naufalpratama@umy.ac.id \\ *korespondensi penulis
}

Naskah diterima: 28 Juli 2020, direvisi: 20 Agustus 2020, disetujui: 13 September 2020

\begin{abstract}
Abstrak
Hukum Humaniter Internasional (HHI), yang juga dikenal sebagai Hukum Kemanusiaan Internasional adalah salah satu cabang dari Hukum Internasional yang sangat penting untuk diketahui dan dipelajari, tidak hanya bagi Anggota Palang Merah, personel Militer serta Kepolisian, namun juga kepada seluruh masyarakat Indonesia, terutama para para pemuda. Perlunya program diseminasi sejak dini ini, adalah upaya untuk membatasi korban konflik bersenjata, menjamin dan melindungi korban konflik, menumbuhkan peran dalam kemanusian, dan menyebarkan semangat perdamaian. Program pengabdian masyarakat ini pada dasarnya merupakan tanggung jawab bagi seluruh negara peserta Konvensi-Konvensi Jenewa 1949, namun tentu saja negara akan banyak mengalami keterbatasan untuk menjangkau seluruh anggota masyakarat Indonesia, untuk itu diperlukanlah program pengabdian masyarakat berupa diseminasi HHI itu sendiri. Program pengabdian masyarakat ini akan menyasar para siswa SMA Muhammadiyah yang berada di Kota Yogyakarta. Kegiatan Diseminasi HHI ini akan berupa seminar dari narasumber yang merupakan pengajar dan pembelajar HHI dari Universitas Muhammadiyah Yogyakarta, diskusi kelompok serta role play berupa TFG (Tactical Floor Game). Diharapkan setelah mengikuti program ini, peserta dapat memahami serta menjunjung tinggi penghormatan terhadap HHI dan perlindungan terhadap lambang palang merah dan bulan sabit merah, serta mampu mengaplikasikan ilmu yang didapat, terutama dalam proses penyelesaian konflik, menjunjung tinggi perdamaian, serta berperan aktif dalam aktivitas kemanusiaan.

Kata-kata Kunci: Hukum Humaniter Internasional, Diseminasi, Konvensi Jenewa 1949
\end{abstract}

\begin{tabular}{l} 
Abstract \\
\hline International Humanitarian Law (IHL), is one of a very important branch of International Law \\
that needs to be disseminated not only to Red Cross, Military, or Police Personnel, but also to \\
the public as a whole, especially the youth. The need of this dissemination program is to limit \\
the casualties from an armed conflict, to guarantee and secure the victims of war, encourage \\
participation in humanity, and spread the spirit of peace. This community service program is an \\
obligation for all countries that are party to the Geneva Convention 1949, yet the country alone \\
will face difficulty to reach all the elements of the society. Therefore, there is a need for a \\
community service program to disseminate IHL. This program is the senior high school students \\
in Yogyakarta. The dissemination will be conducted in forms of seminar delivered by the speaker \\
which is a lecturer and a researcher in Universitas Muhammadiyah Yogyakarta, group \\
discussion and role playing in a form of TFG (tactical Floor Gaming). After participating in this \\
program, the participants are expected to understand and uphold the IHL and protection to the \\
Red Cross and Red Crescent emblem, and able to implement the gained knowledge, especially \\
in conflict resolution, upholding peace, and actively participate in humanity activity.
\end{tabular}

Keywords: International Humanitarian Law, Dissemination, Geneva Convention 1949 


\section{PENDAHULUAN}

Ancaman konflik bersenjata atau peperangan adalah ancaman yang nyata dan dapat terjadi di bagian bumi dimana saja. Kita tidak akan pernah tahu kapan peperangan itu akan terjadi di negara kita. Langkah terbaik adalah untuk bersiap-siap, seperti yang dikatakan oleh pepatah latin Si Vis Pacem Para Bellum (jika menginginkan kedamaian, maka bersiaplah untuk perang). Konflik dan kekerasan yang terjadi di berbagai belahan dunia adalah suatu tragedi kemanusiaan dan suatu yang sangat disayangkan.

Perdamaian adalah suatu hal prestisius yang dicita-citakan oleh setiap bangsa dan negara. Negara-negara di dunia telah bersepakat untuk ikut bersama-sama dalam menjaga perdamaian dunia dan membentuk organisasi internasional yang bernama United Nations yang mana tujuan utamanya adalah demi menjaga keamanan dan kedamaian dunia seperti yang tertuang pada pasal 1 Piagam Perserikatan Bangsa Bangsa. Indonesia pun telah menunjukan komitmennya untuk ikut serta dalam menegakkan dan menjaga perdamaian dunia dengan bergabung dalam Perserikatan Bangsa Bangsa, serta menjadi salah satu negara penandatangan Konvensi Jenewa 1949. Komitmen ini juga dituangkan didalam pembukaan UUD Dasar Negara Republik
Indonesia 1945, yang berbunyi "ikut melaksanakan ketertiban dunia yang berdasarkan kemerdekaan, perdamaian abadi dan keadilan sosial".

Kata "damai" biasa diartikan keadaan dimana itu tidak adanya kekerasan. Sedangkan beberapa lainnya mengartikan kedamaian sebagai keadaan tenang dimana tidak ada selisih dan pertentangan dimana orang-orang secara individu maupun kelompok masyarakat hidup dengan tenang.

Hukum humaniter internasional adalah seperangkat aturan untuk alasan kemanusiaan, membatasi efek konflik bersenjata. Melindungi orang yang bukan atau tidak lagi berpartisipasi dalam konflik, juga membatasi sarana dan metode perang. Hukum Humaniter Internasional juga dikenal sebagai hukum perang atau hukum konflik bersenjata. Hukum humaniter internasional adalah bagian dari hukum internasional, yaitu sekumpulan aturan yang mengatur hubungan antar negara.

Hukum internasional adalah hukum yang terkandung dalam perjanjian antar Negara, Konvensi, Kebiasaan Internasional, yang terdiri dari Praktek kenegaraan yang kemudian memiliki kekuatan mengikat secara hukum, serta mengandung prinsip-prinsip umum (ICRC, 2004). 
Konvensi Jenewa 1906 dan 1929 mewajibkan negara-negara untuk mengambil langkah-langkah yang diperlukan agar Konvensi tersebut diketahui oleh penduduk pada umumnya (Konvensi Jenewa, 1949). Konvensi Jenewa 1949 dan Konvensi Den Haag untuk Perlindungan Kekayaan Budaya mengharuskan Negara untuk memasukkan studi hukum humaniter internasional ke dalam program pelatihan sipil mereka "jika memungkinan" (Lubis, M, 2017:1). Protokol Tambahan I dari Konvensi Jenewa sendiri juga mengharuskan Negara-negara untuk menyebarkan hukum humaniter internasional seluas mungkin dan, khususnya lebih mendorong memasyarakatkan HHI sendiri kepada penduduk sipil (Protokol Tambahan 1, Pasal 83).

Kewajiban negara untuk mendorong studi hukum humaniter internasional oleh penduduk sipil atau untuk menyebarkan hukum humaniter internasional seluas mungkin sehingga diketahui oleh penduduk sipil, bahkan disebutkan juga dalam banyak aturan militer. Selain itu, undang-undang beberapa negara mengatur bahwa penduduk sipil harus menerima instruksi dalam hukum humaniter internasional atau memasukkan ketentuan yang secara langsung bertujuan untuk memenuhi syarat wajib memperkenalkan HHI.
Dalam praktiknya, banyak Negara memfasilitasi kursus ataupun pelatihanpelatihan hukum humaniter internasional, dengan penyandang dana yang berasal dari organisasi penggerak kemanusiaan, seperti Palang Merah Nasional atau Masyarakat Bulan Sabit Merah. Menurut Statuta Gerakan Palang Merah dan Bulan Sabit Merah Internasional, Perhimpunan Nasional wajib "menyebarkan dan membantu pemerintah mereka dalam menyebarkan hukum humaniter internasional; mereka mengambil inisiatif dalam hal ini " (Statutes of the International Red Cross and Red Crescent Movement, Article 3). Selain itu, lebih dari 60 negara telah membentuk komite nasional tentang hukum humaniter internasional yang tugasnya biasanya mencakup penyebaran dan promosi (ICRC Advisory Service, Table of National Committees on International Humanitarian Law, 2002).

Semakin banyak institusi pendidikan tinggi yang mulai menawarkan kursus hukum humaniter internasional terutama dalam waktu beberapa tahun terakhir. Selain itu, Dewan Keamanan PBB, Majelis Umum serta Komisi Hak Asasi Manusia PBB sendiri, serta Dewan Eropa dan Organisasi Persatuan Afrika, telah meminta atau mengundang negara-negara untuk menyebarkan hukum humaniter internasional atau untuk mempromosikan pengajarannya kepada 
penduduk sipil (Lubell \& Cohen, 2002:96). Sebagai salah satu bagian Hukum Internasional, Hukum Humaniter Internasional, HHI sendiri merupakan salah cara yang dapat digunakan oleh setiap negara, termasuk oleh negara damai atau negara netral, untuk ikut serta mengurangi penderitaan dan kerusakan yang diakibat perang yang terjadi.

HHI yang merupakan instrumen kebijakan dan sekaligus menjadi pedoman teknis yang dapat digunakan oleh semua negara di dunia serta actor internasional lainnya untuk mengatasi isu internasional berkaitan dengan kerugian dan korban perang (Rusman, 2013). Dengan semakin banyaknya negara yang mengakui nilai-nilai yang terdapat di dalam HHI, maka semakin tinggi pula tingkat penghormatan dan pelaksanaan HHI oleh negara damai ataupun negara yang terlibat dalam perang sendiri.

Sebagai salah satu pihak peserta Konvensi Jenewa 1949, maka sudah seharusnya pemerintah Indonesia melakukan diseminasi (penyebarluasan) Konvensi Jenewa 1949. Pada dasarnya, pihak yang memiliki tanggung jawab besar untuk menyebarluaskan Hukum Humaniter Internasional (HHI) sendiri adalah pemerintah suatu negara di seluruh dunia, tanpa kecuali. Namun disisi lain, mengandalkan pemerintah saja tidak akan cukup untuk mencakup semua lini di Indonesia, maka dari itu dibutuhkan pula bantuan dari lembaga-lembaga seperti palang Merah Indonesia, termasuk juga dari kalangan akademisi.

\section{Melalui Program pengabdian} masyarakat ini, tim program pengabdian mencoba untuk menanamkan dan mengokohkan rasa cinta damai dan meningkatkan kepedulian akan nilai nilai kemanusiaan dikalangan remaja melalui diseminasi Hukum Humaniter Internasional dengan menggunakan metode Seminar dan Role Play yang diselenggarakan bersama dengan SMA Muhammadiyah 1 Yogyakarta dan SMA Muhammadiyah 2 Yogyakarta.

Model penyampaian seminar dikemas dalam suasana diskusi interaktif yang bersifat non-formal sehingga memacu keingintahuan para pelajar lebih maksimal dalam menggali materi-materi kegiatan. Adapun materi yang disampaikan adalah tentang pentingnya memahami keberagaman dan semangat perdamaian agar dapat memberdayakan kaum muda dan mendorong partisipasi aktif dalam mengintegrasikan nilai-nilai dan prinsipprinsip perdamaian ke dalam semua bidang kehidupan sekolah dan sehari-hari. Dengan pendekatan "role playing” (participatory learning), para partisipan dibuat lebih santai dan atraktif dengan penyajian beberapa simulasi dan contoh-contoh kasus 
aktual/kontekstual terkait dengan konflik bersenjata, bencana alam, dan keadaan krisis.

Tujuan dari diseminasi Hukum Humaniter Internasional di kalangan siswasiswi di kota Yogyakarta ini adalah untuk menyebarkan pengetahuan dan mengembangkan pemahaman mengenai HHI dan isu-isu kemanusiaan dan etika terkait, yang relevan pada masa damai maupun situasi konflik bagi para remaja di kota Yogyakarta sehingga dapat diwujudkannya para remaja yang memahami rasa cinta damai dan meningkatkan kepedulian akan nilai nilai kemanusiaan serta menjunjung tinggi lambang palang merah dan bulan sabit merah, serta mampu mengaplikasikan ilmu yang didapat, terutama dalam proses penyelesaian konflik, menjunjung tinggi perdamaian, serta berperan aktif dalam aktivitas kemanusiaan.

Program ini dapat menjadi role model serta sarana memupuk rasa dan nilai-nila kemanusiaan dalam jiwa para siswa, karena peran dari hukum humaniter internasional sendiri tidak hanya dalam hal menciptakan perdamaian dunia dan perlindungan korban konflik bersenjata, tetapi juga pada misi-misi kemanusiaan lainnya, seperti bencana alam yang membuat masyarakat menjadi korban yang mengalami kerugian secara fisik dan kerugian non-fisik lainnya.

\section{METODE}

Lokasi pengabdian ini dilaksanakan di SMA Muhammadiyah 1 dan SMA Muhammadiyah 2 Yogyakarta di Kota Yogyakarta. Pelaksanaan Kegiatan Pada bulan Januari-Maret 2020.

Khalayak sasaran dalam kegiatan adalah para pelajar (siswa siswi) SMA Muhammadiyah 1 dan SMA Muhammadiyah 2 Yogyakarta sebagai penerima manfaat. Kelompok sasaran ini sengaja dipilih dengan pertimbangan: (a) memiliki reputasi sebagai salah satu sekolah unggulan/favorit di Yogyakarta, para siswanya diasumsikan mempunyai kemampuan diatas rata-rata sehingga akan mudah memahami materi kegiatan, (b) merepresentasikan jumlah siswa/siswi dikalangan pelajar atau di sekolah-sekolah menengah atas (SMA/ Madrasah Aliyah) se-Daerah Istimewa Yogyakarta, (c) Pelajar SMA yang berperan penting dalam menanamkan dan mempraktekan nilai-nilai perdamaian dan c) menjunjung tinggi $\mathrm{HHI}$; (d) diasumsikan mempunyai animo partisipasi dalam Program Diseminasi Hukum Humaniter Internasional, oleh karena itu perlu, pendidikan penanaman nilai-nilai perdamaian sejak dini yang mencerdaskan sesuai indikator/kategori yang telah dipetakan oleh Tim pelaksana kegiatan. 


\section{Tahap Awal Persiapan.}

Tim melakukan koordinasi dan komunikasi terlebih dahulu dengan pihak pimpinan SMA Muhammadiyah 1 Yogyakarta dan SMA Muhammadiyah 2 Yogyakarta pada Minggu Pertama, Minggu Kedua, dan Minggu Ketiga, untuk memastikan terselenggaranya kegiatan pengabdian dimaksud sesuai target dan waktu yang telah ditentukan. Selanjutnya pada Minggu Keempat, Tim melakukan rangkaian rapat/meeting koordinasi teknis internal yang mencakup diantaranya:

a. Melakukan rapat orientasi personil secara internal.

b. Proses pendistribusian beban dan tanggung jawab kerja.

c. Menyamakan persepsi tentang dinamika kerja.

d. Target yang ingin dicapai, penentuan tugas antar staf.

e. Rapat penyiapan teknis kelengkapan acara/kegiatan.

\section{Tahap Pelaksanaan.}

Pada Maret 2020 merupakan fase terakhir/final dari pelaksanaan kegiatan pengabdian. Kelompok sasaran penerima manfaat yang sudah teridentifikasi, diasumsikan mereka belum memiliki pengetahuan dan tingkat kesadaran yang memadai mengenai pentingnya pendidikan Hukum Humaniter Internasional yang mencerdaskan bagi pelajar, hal ini dibuktikan dengan pelaksanaan pre-test kepada para peserta. Karenanya, materi dalam pelaksanaan kegiatan ini setidaknya mencakupnya: (a) arti penting/implikasi Perdamaian; (b) pentingnya memahami keberagaman sesama pelajar, dan (c) memberdayakan kaum muda dan mendorong partisipasi aktif semua anggota komunitas sekolah dalam mengintegrasikan nilai-nilai dan prinsip-prinsip perdamaian ke dalam semua bidang kehidupan sekolah dan seharihari.

Pelaksanaan kegiatan dalam bentuk seminar dan model participatory learning atau “role playing” (Widjajanti, 2011:12). Model penyampaiannya dikemas/dirangkai dalam suasana diskusi interaktif yang bersifat nonformal sehingga memacu keingintahuan para pelajar lebih maksimal dalam menggali materi-materi kegiatan. Dengan pendekatan "role playing" (participatory learning), para partisipan dibuat lebih santai dan atraktif dengan penyajian beberapa simulasi dan contoh-contoh kasus aktual/kontekstual terkait dengan konflik bersenjata, bencana alam, dan keadaan krisis.

Adapun teknik pelaksanaannya, meliputi: (a) identifikasi calon peserta dengan target tingkat partisipasi sebesar $80 \%$ dari total jumlah siswa/siswi di SMA Muhammadiyah 1 Yogyakarta dan SMA 
Muhammadiyah 2 Yogyakarta, (b) evaluasi dan bahan laporan bulanan. mengundang peserta yang telah Mekanisme monitoring dan evaluasi teridentifikasi, (c) menyiapkan ATK kegiatan dilaksanakan secara partisipatoris. Setiap dan tempat kegiatan, (d) menyiapkan konsumsi meeting/acara (e) mengundang akhir kegiatan, partisipan dimintai narasumber/fasilitator, (f) ceramah pengantar diskusi/kegiatan dari yang mewakili pimpinan SMA Muhammadiyah $1 / 2$ Yogyakarta, yang dipandu pembawa acara, (g) Penyampaian materi oleh narasumber/fasilitator, dan (h) diskusi langsung dengan alur interaktif/participatory learning antara para peserta/partisipan dengan narasumber (i) simpulan dan rekomendasi.

Sejumlah indikator keberhasilan yang menjadi tolok ukur, sebagai berikut : (a) pengetahuan akan nilai-nilai perdamaian dan kemanusiaan makin meningkat (b) meningkatnya kesadaran akan pentingnya Hukum Humaniter Internasional, serta menghormati lambang palang merah dan bulan sabit merah, (c) mampu menerapkan dan menjunjung tinggi nilai-nilai perdamaian dalam kehidupan sehari-hari, melalui hasil evaluasi berupa Post Test bagi para peserta, yang juga menjalani aktivitas pre-test di awal aktifitas..

Hal-hal yang dimonitoring dan dievaluasi (Monev) adalah keseluruhan progres pelaksanaan kegiatan dari tahap awal persiapan hingga akhir pelaksanaan. Hasil monitoring dan evaluasi akan dijadikan bahan pendapatnya mengenai dampak positif yang dirasakan oleh para partisipan termasuk memberikan masukan untuk kegiatan serupa di masa mendatang dengan kelompok sasaran/partisipan lain di kalangan pelajar di lingkungan sekolah SMA/SMK/Aliyah di D.I. Yogyakarta. Hasil evaluasi partisipan akan dikomparasikan dengan hasil pengamatan staff terhadap pelaksanaan kegiatan sehingga bisa mendapatkan jawaban-jawaban secara objektif. Dengan demikian stakeholders yang terlibat sebisa mungkin dilibatkan dalam monitoring dan evaluasi kegiatan ini.

Diharapkan sejumlah gagasan /ide /kontribusi pemikiran yang lahir dari para partisipan/narasumber, dapat melahirkan design program lanjutan yang lebih luas jangkauannya serta tidak terbatas dikalangan pelajar. Melalui program ini, para partisipan/mitra akan termotivasi untuk berpartisipasi aktif dan tidak apatis untuk mengimplementasikan dan menjunjung nilainilai perdamaian. Program ini bisa menjadi role model/pilot project dan bahkan para partisipan bisa menjadi kelompok katalisator, yang mendorong kelompok (calon partisipan) lain dikalangan pelajar di Yogyakarta untuk 
melibatkan diri atau melakukan kegiatan yang sama demi terwujudnya generasi muda yang sadar akan pentingnya perdamaian.

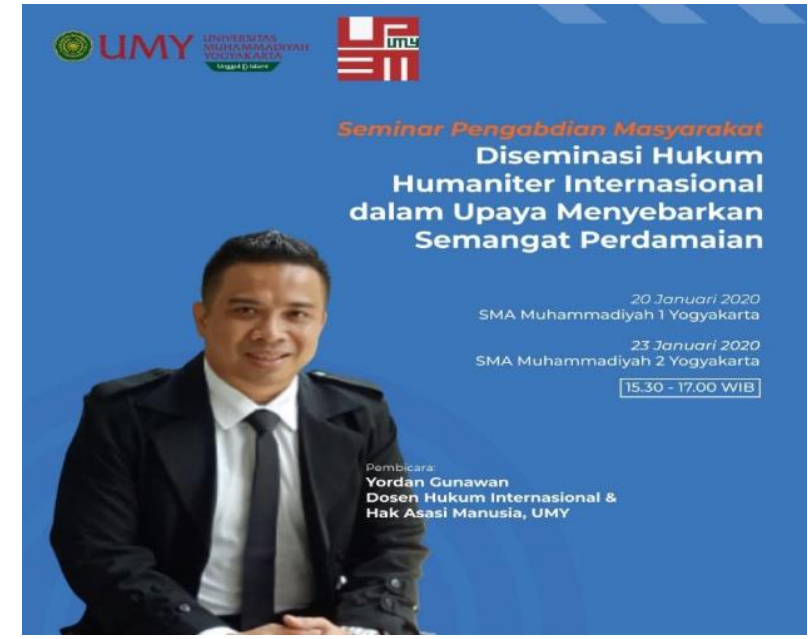

Sumber: Dokumentasi Penulis, 2020 Gambar 1. Kegiatan Seminar di SMA Muhammadiyah 1 dan 2 Yogyakarta

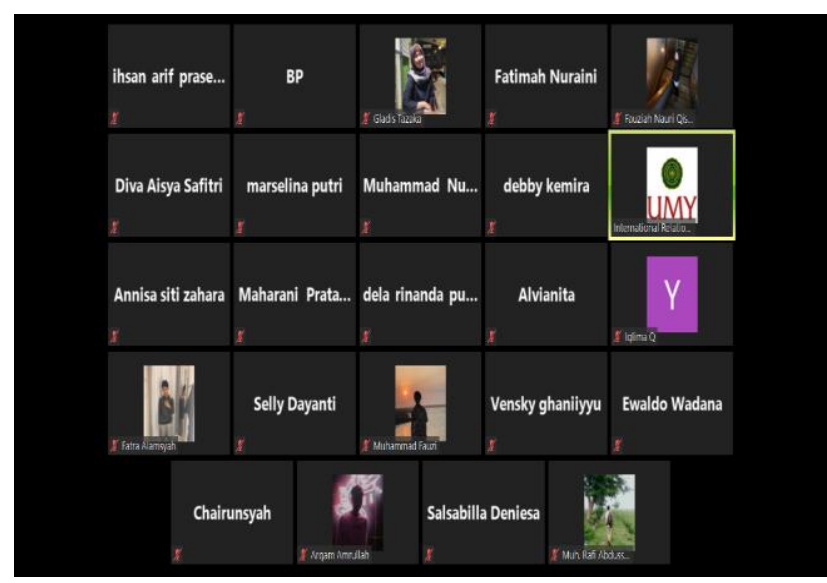

Sumber: Dokumentasi Penulis, 2020 Gambar 2. Kegiatan Seminar di SMA Muhammadiyah 1 dan 2 Yogyakarta

Gambar 1 dan 2 menunjukkan bahwa kegiatan ceramah yang dilakukan oleh tim dosen pengabdi. Adapun target dari program seminar ini adalah bagaimana siswa-siswi dari SMA Muhammadiyah 1 dan 2 Yogyakarta mengerti bagaimana pentingnya mengimplementasikan dan menjunjung tinggi nilai-nilai perdamaian dalam kehidupan sehari-hari. Program seminar ini juga 
difungsikan sebagai ajang diskusi berkaitan dengan persoalan-persoalan seputar Hukum Humaniter Internasional dan perdamaian dunia serta problem-problem yang terkait, sekaligus mencari solusi terhadap persoalan tersebut demi terciptanya siswa-siswi yang memahami, mengimplementasikan, dan menjunjung tinggi nilai-nilai perdamaian.

Dalam program ini, para siswa-siswa memainkan peran sebagai elemen-elemen yang terlibat dalam simulasi bencana alam metode "role playing" yang menuntut keterlibatan peserta secara aktif dalam simulasi. Tujuan metode ini adalah untuk menanamkan nilai-nilai tanggung jawab sebagai warga negara dan manusia secara umum dalam kehidupan sehari-hari. Kegiatan role playing dapat ditunjukkan pada gambar 3 berikut.

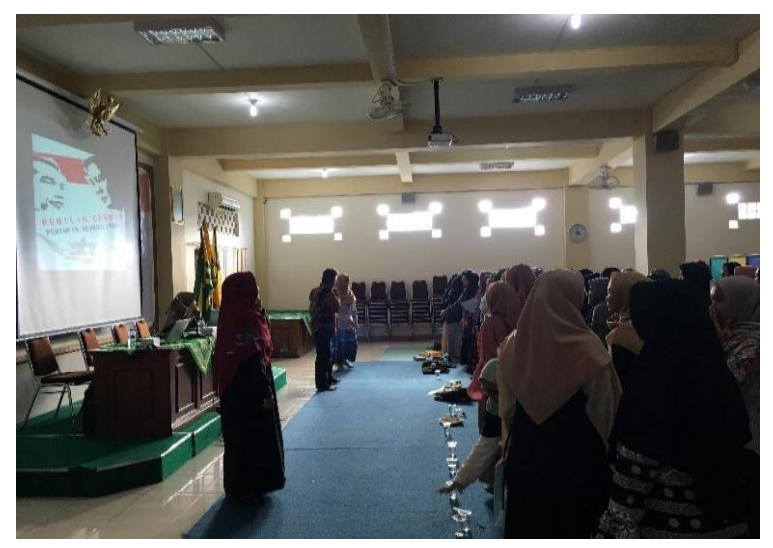

Sumber: Dokumentasi Penulis, 2020

Gambar 3. Kegiatan Role Playing

\section{KESIMPULAN}

Kesimpulan dari rangkaian kegiatan ini diharapkan melalui program ini, para pelajar dapat memahami fungsi hukum humaniter internasional dalam menjamin adanya perdamaian dunia dan menjunjung tinggi nilai-nilai kemuanisaan dalam hidup bermsyarakat. Program pengabdian pada masyarakat ini juga diharapkan menjadi bagian penting dalam peningkatan pemahaman akan nilai-nilai perdamaian di kalangan siswa-siswi sejak dini, sehingga di masa depan, siswa siswi diharapkan menjadi pemimpin yang memiliki rasa cinta damai. Memperkuat rasa dan nilai-nilai humanis dan kemanusiaan dalam jiwa para siswa, karena peran dari hukum Humaniter sendiri tidak hanya dalam hal menciptakan perdamaian dunia dan perlindungan korban konflik bersenjata, tetapi juga pada misi-misi kemanusiaan lainnya.

Program ini juga dapat menjadi role model dimana para partisipan, diharapkan akan menjadi inisiator yang mendorong kelompok (calon partisipan) lainnya dan tidak terbatas di kalangan pelajar di Yogyakarta untuk melibatkan diri atau melakukan hal yang sama demi terwujudnya siswa-siswi yang memahami dan menjunjung tinggi semangat perdamaian. 
Guna mendapatkan hasil yang lebih baik bagi para pelaksana aktivitas pengabdian masyarakat ini di masa depan, maka penulis memberikan saran untuk agar aktivitas pengabdian masyarakat ini, tidak hanya dilakukan di dua Sekolah Menengah Atas saja, sehingga jangkauan diseminasi bisa dilakukan dengan jauh lebih luas, baik dari sisi jumlah peserta yang mendapatkan manfaat, tetapi juga dilakukan kepada masyarakat pada umumnya.

\section{UCAPAN TERIMAKASIH}

Penulis dalam kegiatan ini menyampaikan apresiasi dan terima kasih kepada Pihak Universitas Muhammadiyah Yogyakarta, Kepala Sekolah SMA Muhammadiyah 1 Yogyakarta dan SMA Muhammadiyah 2 Yogyakarta, para siswa/siswi partisipan, serta semua pihak lain terlibat dalam kegiatan ini.

\section{REFERENSI}

Geneva Convention for the Protection of the

Wounded and Sick, Article 26, 1929

Geneva Convention for the Protection of the

Wounded and Sick, Article 27.
ICRC, Advisory Service, Table of National Committees on International Humanitarian Law. (2002).

ICRC, Advisory Service on International Humanitarian Law. (2004).

Lubell, N \& Cohen, A . (2002). Strategic Proportionality: Limitations on the Use of Force in Modern Armed Conflicts. International Law Studies 96(1).

Lubis, M. (2017). The Relationship of International Human Rights Law with International Humanitarian Law in Situations of International Armed Conflicts. Journal of Indonesian Legal Studies. 1(1).

Piagam Perserikatan Bangsa Bangsa.

Protokol Tambahan 1, Pasal 83.

Rusman, R. (2013). Hukum Humaniter Internasional dalam Studi Hubungan Internasional. Rajagrafindo Persada.

Statutes of the International Red Cross and Red Crescent Movement, Article 3(2). Undang Undang Dasar Negara Republik Indonesia 1945.

Widjajanti, K. (2011). Model pemberdayaan masyarakat. Jurnal Ekonomi Pembangunan. 12(1). 